\title{
Unsaturated Polyester for Large Castings
}

\author{
Abdel-Azim A. Abdel-Azim,* E. S NaSr, and M. S. Farhat \\ Egyptian Petroleum Research Institute, Nasr City, Cairo, Egypt
}

(Received July 27, 1993)

\begin{abstract}
A series of unsaturated polyesters based on phthalic anhydride (PHA), maleic anhydride (MA), ethylene glycol (EG), diethylene glycol (DG), triethylene glycol (TG), propylene glycol (PG), and styrene (Sty) were prepared. The molecular weights of the prepared polyesters were determined by the end group analysis. The crosslinking of unsaturated polyesters by copolymerization reaction between the double bonds from maleic anhydride and styrene has been studied. The effect of the structure of the resin on its curing behavior has been investigated. A marked delay in cure has been observed when EG was replaced or combined with other glycols. The maximum curing temperature, Young's modulus and compressive strength were found to be related to the molecular weight of the glycol incorporated in these castings.
\end{abstract}

KEY WORDS Unsaturated Polyester / Curing / Preparation / Synthesis /

Styrene / Curing Exotherm / Mechanical Properties /

Unsaturated polyester resins are very versatile in their applications. They are used in the fabrication of a broad range of products. Consequently, there are a variety of resin formulations, depending on specific applications as well as fabrication processes.

Unsaturated polyester resins are produced by reacting an unsaturated dibasic acid or a mixture thereof with a saturated dibasic acid with a polyhydric alcohol, and then adding a polymerizable unsaturated monomer. These unsaturated polyester resins can be polymerized and cured in the presence of a polymerization catalyst such as an organic peroxide. Copolyesters of various diols and mixtures of saturated, and unsaturated acids permit a wide range of properties to be obtained with the use of vinyl monomer. On the other hand, some work has been done on the production of polyester resins based on recycled poly(ethylene terephthalate), PET., ${ }^{1,2}$ The purified PET scrap was depolymerized using different glycols into glycolized monomers and oligomers. These oligomers were then reacted with unsaturated dibasic acids or anhydrides to form unsaturated polyester resins. The properties of polymer concrete obtained from resins based on recycled PET were extensively studied and were found to be comparable to polymer concrete made from virgin materials. ${ }^{3-5}$

When large objects are cast from highly polymeric resins, frequently the highly exothermic reaction, has been a considerable problem. The cross-linking reaction of unsaturated polyester is a highly exothermic process, and heat thus liberated tends to rise the mold temperature and accelerate the curing reaction. Consequently, the physical and mechanical properties of a thermosetting material depends upon the extent of the polymerization reaction during cure or upon the degree of cure in the molded material. Determining such dependence is not only important for better understanding of structureproperty relationships, but it is also funda-

\footnotetext{
* To whom all correspondence should be addressed.
} 
mental in optimizing the properties of the final product. Therefore, the control of the rate of heat generation and the temperature variations during the processing of these materials is very important in order to achieve the desired degree of cure of the final product. However, the rate of the polymerization reaction is dependent upon the temperature and the type and the concentration of the monomer and initiator used. An experimental design was developed to study the effect of initiator and accelerator concentrations on the amount of heat evolved upon curing and the mechanical properties of the cured resins. ${ }^{6}$

The present investigation pertains to the preparation of thermosetting materials permitting the casting of large sized objects and eliminating from such casting the difficulties encountered due to the excessive heat of curing. This can be attained by: (1) altering the polyhydric alcohol, such as ethylene (EG), propylene (PG), diethylene (DG), or triethylene (TG) glycols, combinations during preparation of the unsaturated polyesters; (2) varying the ratio of unsaturated dibasic acid to the saturated one. Measuring the curing temperature as a function of time and the compressive characteristics of the cured resins are the methods to be used to categorize and rank the various thermosetting resins.

\section{EXPERIMENTAL}

\section{Materials}

Polyhydric alcohols (EG, DG, TG, and PG), phthalic anhydride (PHA), maleic anhydride (MA), and styrene were reagent grade and used without further purification. All chemicals were obtained from Aldrich.

\section{Preparation of Unsaturated Polyesters (UP)}

The UP resins were prepared by reacting the appropriate amounts of saturated, unsaturated acid or acid anhydrides, and glycols according to the ratios tabulated in Table I. Nine different UP were prepared by adopting the method described in ref 7 . The acid number is determined by the conventional method ${ }^{8}$ and the molecular weight of each UP was determined by end group analysis. ${ }^{7}$ The UP resins were analyzed for acid and hydroxyl values, for the sake of calculating the molecular weights, before blending these with Sty monomer to give $60 \%$ solution of the polyester.

\section{Determination of Acid Number}

The acid number of a resin is defined as the number of $\mathrm{mg}$ of potassium hydroxide required to neutralise $1 \mathrm{~g}$ of resin. Accordingly, the acid number was obtained by titrating the solution of an accurate weight of resin, about $2 \mathrm{~g}$, in

Table I. Composition of different formulae of unsaturated polyester resins and their relivant acid values and the equivalent polymerizable double bonds (EPDB)

\begin{tabular}{|c|c|c|c|c|c|c|c|c|}
\hline \multirow{3}{*}{ No. } & \multicolumn{6}{|c|}{ Composition } & \multirow{3}{*}{$\begin{array}{l}\text { Acid } \\
\text { value }\end{array}$} & \multirow{3}{*}{ EPDB } \\
\hline & \multicolumn{2}{|c|}{ Acid $/ \mathrm{mol}$} & \multicolumn{4}{|c|}{ Glycol/mol } & & \\
\hline & PHA & MA & EG & DG & TG & PG & & \\
\hline 1 & 0.5 & 0.5 & 1.10 & - & - & - & 18 & 0.265 \\
\hline 2 & 0.5 & 0.5 & 0.55 & 0.55 & - & - & 19 & 0.237 \\
\hline 3 & 0.5 & 0.5 & 0.55 & - & 0.55 & - & 22 & 0.214 \\
\hline 4 & 0.5 & 0.5 & 0.55 & - & - & 0.55 & 27 & 0.255 \\
\hline 5 & 0.5 & 0.5 & - & 0.55 & - & 0.55 & 32 & 0.229 \\
\hline 6 & 0.5 & 0.5 & - & 0.55 & 0.55 & - & 19 & 0.195 \\
\hline 7 & 0.5 & 0.5 & - & - & 1.10 & - & 26 & 0.179 \\
\hline 8 & 0.25 & 0.75 & - & 0.55 & - & 0.55 & 26 & 0.365 \\
\hline 9 & 0.75 & 0.25 & - & 0.55 & - & 0.55 & 37 & 0.108 \\
\hline
\end{tabular}


acetone solvent $(25 \mathrm{ml})$ with $N / 1 \mathrm{KOH}$ using phenolphthalein as indicator. The volume of the $\mathrm{KOH}$ solution (in $\mathrm{ml}$ ), at the end point, and the weight of the sample were used for evaluating the acid number from the equation:

acid number $=$

$(\mathrm{ml} \mathrm{N} / 1$ standard alkali $\times 56.1) /$ weight of sample

\section{Determination of Peak Exotherm}

The curing exotherm of the copolymerization reaction between the monomer and unsaturated polyester were measured by Digitron digital differential thermometer, type $\mathrm{K}$, model 3202 with a resolution $0.1^{\circ} \mathrm{C}$, kindly provided by Geochem Group Ltd., Chester, England. The reaction mixture was thermostated at $35^{\circ} \mathrm{C}$ for about $5 \mathrm{~min}$. When the temperature of the mixture attained $35^{\circ} \mathrm{C}$, the appropriate amount of accelerator and initiator were added successively and mixed thoroughly for $1 \mathrm{~min}$. The reaction mixture was poured into two test tubes and a glass bottle of $5 \mathrm{ml}$ volume. The resin in the test tubes was cured to prepare the specimens required for measuring the mechanical properties whereas that in the glass bottle was for measuring the curing exotherm. Since the amount of heat evolved upon curing depends on the sample size, it was very important to consider this parameter. For this reason it was desirable to use glass bottles of the same volume in all measurements. The thermocouple probe of the digital thermometer was immersed in a narrow tube containing silicon oil which was inserted into the bulk of the reaction mixture placed in the glass bottle. The reaction temperature was reported at different times. It is of interest to mention that the zero time was considered as the moment at which the initiator is added to the reaction mixture. The recorded temperatures were plotted versus time. The maximum curing temperature $\left(T_{\max }\right)$ could be detected as the highest value in the curve, peak exotherm temperature $\left(T_{\max }\right)$, whereas $t_{\max }$ is the time required to reach $T_{\max }$.
To elucidate the influence of composition of the reaction mixture on the curing temperature and curing time, the concentration of methyl ethyl ketone peroxide, MEKP (initiator) and cobalt octoate, $\mathrm{CO}$ (accelerator) were kept constant allover the curing reactions. The formulation used for curing was resin/initiator/accelerator $=100 / 2 / 0.2$ (parts by weight) ${ }^{6}$

\section{Mechanical Properties}

The clear cast resins were evaluated for their compressive properties according to ASTM D695. The cross-head speed was $1.3 \mathrm{~mm}$ $\min ^{-1}$. The speed was increased to $5 \mathrm{~mm} \mathrm{~min}^{-1}$ after the yield point, for relatively ductile samples. The stress-strain diagrams were measured using a Zwick mechanical testing machine as described in the previous work. ${ }^{6}$

\section{RESULTS AND DISCUSSION}

\section{Molecular Weight}

Molecular weight determination through end group analysis requires that the polymer contains a known number of determinable groups per molecule. The long-chain nature of polymers limits such groups to be the end groups. Thus the method is usually referred to as end group analysis. ${ }^{9}$ Since methods of end group analysis count the number of molecules in a given weight of sample, they yield the number-average molecular weight for polydisperse materials. The method become insensitive at high molecular weight, as the fraction of end groups becomes too small to be measured with precision. Although published procedures $^{9}$ often indicate that loss of precision occurs at molecular weights above 25000 , there is no doubt that the adoption of more sensitive techniques, such as gas chromatography or mass spectrometry to estimate the reaction products, can rise this limit by at least a factor of 10 . Similar consideration apply to the use of infrared spectroscopy to measure end groups. End group analysis in condensation polymers usually involves chemical 
Table II. Molecular weights, curing behavior and mechanical properties of unsaturated polyesters (formulae 1-9)

\begin{tabular}{cccccc}
\hline No. & Molwt & $t_{\max } / \min$ & $T_{\max } /{ }^{\circ} \mathrm{C}$ & $\sigma_{\mathbf{u}} / \mathrm{MPa}$ & $E / \mathrm{GPa}$ \\
\hline 1 & 2438 & 8 & 70.5 & 141.7 & 0.828 \\
2 & 2123 & 16 & 49.0 & 183.0 & - \\
3 & 2010 & 15 & 41.0 & 114.0 & - \\
4 & 1796 & 15 & 47.0 & 122.0 & 0.800 \\
5 & 1543 & 16 & 43.7 & 160.2 & 0.728 \\
6 & 2230 & 18 & 38.5 & 134.0 & - \\
7 & 1814 & 42 & 37.5 & 113.6 & - \\
8 & 1772 & 14 & 56.5 & 187.2 & 1.372 \\
9 & 1580 & 25 & 37.0 & 99.8 & - \\
\hline
\end{tabular}

methods of analysis for functional groups. Carboxyl and hydroxyl groups, in polyesters, are usually determined by titration methods. ${ }^{10,11}$ The chemical method used in determining the molecular weight of the polyesters prepared in the present study is described in details in ref 7 . The resultant molecular weights are tabulated in Table II in conjunction with other curing characteristics. The highest molecular weight, $M_{n}=2438$, was obtained for formula No. 1 for which the EG was used as a unque glycol for constructing the unsaturated polyester. We believe that the accuracy of the determined values are good enough since the highest molecular weight is less than 25000 as previously established. ${ }^{9}$ When 1,5-pentanediol was used in conjunction with maleic anhydride, for synthesis of unsaturated polyester, Larez et al. ${ }^{12}$ have obtained an unsaturated reasonably high molecular weight polyester, $M_{n}=3307$, as compared with that obtained with lower glycols. ${ }^{13,14}$ A series of unsaturated polyester resins based on fumaric acid, succinic acid and diethylene glycol was prepared by Horie et al. ${ }^{15}$ They have shown that the resultant molecular weights $(2700-3300)$ depend to a large extent on the fumaric-to-succinic mole ratio.

\section{Curing Behavior of Unsaturated Polyester Resins}

An investigation dealing with complex

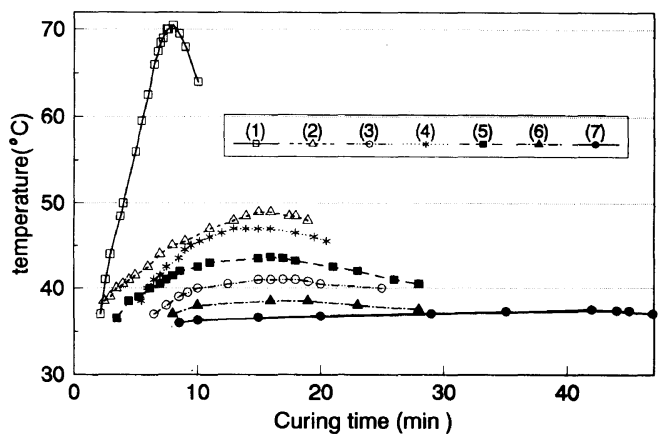

Figure 1. Curing exotherms for UP formulae $1-7$.

systems, such as the curing reactions and processing of thermoset resins, requires a greater attention to all the parameters influence this operation. One of these parameters is the type of the glycols incorporated in the polymers. Another parameter which must be taken into consideration is the cross-linking density. The latter parameter is directly related to the types of acids and the ratio of the unsaturated acid to the saturated one.

Effect of Glycols. The choice of glycols offers great latitude in the deign of polymer backbones. A great variety of glycols is available and glycols often are used in combinations. Figure 1 shows the heat evolved as a factor of curing time for formulae $1-7$. The derived values of $T_{\max }$ and $t_{\max }$ are listed in Table II. It should be pointed out that the maximum curing temperature is related to two different parameters: 1) the molecular weight of glycol, and 2) the equivalent polymerizable double bonds (EPDB) of the unsaturated polyester resin. The relevant values of EPDB for UP formulae are shown in Table I. Comparing the formulae containing EG as one of the components in the main chain of the polymer, reveals that $T_{\max }$ reduces with increasing the molecular weight of the combined glycol. When EG is used alone (formula No. 1), $T_{\max }$ recorded the highest value $\left(70.5^{\circ} \mathrm{C}\right)$. This value reduces to $49^{\circ} \mathrm{C}$ and $41^{\circ} \mathrm{C}$ on replacing half of the quantity of EG with DG and TG (formulae No. 2 and 3) 
respectively. It is of interest to note that the value of $T_{\max }$, for the copolymer containing $\mathrm{EG}+\mathrm{PG}$, (formula No. 4) is slightly lower than that for the copolymer containing EG+DG although the molecular weight of DG is higher than that of PG. This is attributable to the effect of EPDB where it is higher in the former case. It is obvious that the variation of the types of glycols and their combinations leads to different behavior of exothermic temperature. This may be imputed to the differences in the molecular weights of the repeating units of the unsaturated polyesters, consequently, this variation of molecular weights lead to the variation of EPDB. The $T_{\max }$ of the for mula containing DG in conjunction with PG (formula No. 5), as shown in Table II, reduces from $43.7^{\circ} \mathrm{C}$ to $38.5^{\circ} \mathrm{C}$ on replacing $\mathrm{PG}$ with TG (formula No. 6). When TG is used as a sole glycol, $T_{\max }$ reduces to $37.5^{\circ} \mathrm{C}$ as a result of increasing the molecular weight of the glycol portion of the UP chains. This finding confirms the speculation that $T_{\max }$ decreases with increasing the molecular weight of the glycol. This speculation is based on the fact that the higher the molecular weight of the linear glycol the higher the number of carbon atoms in the chain. This leads to more spacing of the unsaturations in UP molecule. Accordingly, the cross-linking density is reduced. It has been mentioned before that the heat evolved upon curing is the result of the cross-linking process. This exothermic heat of curing of the polyester resins comes from the following reactions: (1) the propagation reaction of free-radical crosslinking of the vinyl monomers with an active double bond of the UP, and (2) the decomposition reaction of the peroxide initiator. The heat liberated by reaction (2) is negligible compared to reaction (1). It can be reasonably assumed that the exothermic heat generated per unit mass or volume during an isothermal cure is proportional to the number of double bonds reacted in that unit mass or volume, or in other words, to the cross-linking density. Since EG possesses the lowest chain length compared to all other glycols, under consideration, then it affords the highest cross-linking density and its combination with any glycol of higher molecular weight leads to a reduction in the cross-linking density. Accordingly, the most exothermic curing reaction takes place when EG is used as sole glycol.

Values of $t_{\max }$ for different resins under investigation are also shown in Table II. It is seen that values ranging between 8 and $42 \mathrm{~min}$ are obtained. Here it should be pointed out that a faster curing reaction is obtained when EG is used as a sole glycol. The other types of glycols and their combinations, even with EG, produce unsaturated polyester resins having longer curing times combined with less heat evolved. The slowest curing reaction is obtained for formula No. 7 for which TG is used as a sole glycol. These observations lead to the speculation that increasing the exothermic heat generated per unit mass or volume increases the rate of curing. Consequently, it is equitable to cite that the fast curing time of UP containing EG as a sole glycol is due to its excessive heat of curing which enhances the propagation reaction of free-radical crosslinking.

Effect of Acids. The acid components provide the unsaturation necessary for curing and help to determine the spacing of such unsaturation. Among the unsaturated acid or anhydrides is MA the most widely used. In addition to acting as a source of unsaturation, MA helps to vary the cross-linking density and consequently the mechanical properties of the cured resins.

Figure 2 shows the heat evolved as a factor of curing time for formulae 5, 8 , and 9 . These samples contain the same type and mole ratios of the glycols (DG and PG) while the only difference between them is the MA/PHA mole ratio. The derived values of $T_{\max }$ and $t_{\max }$ are embodied in Table II. It can be easily seen that the percentage of unsaturation in the polyester has a great effect on $T_{\max }$ and $t_{\max }$. This finding may serve as another piece of evidence that the 


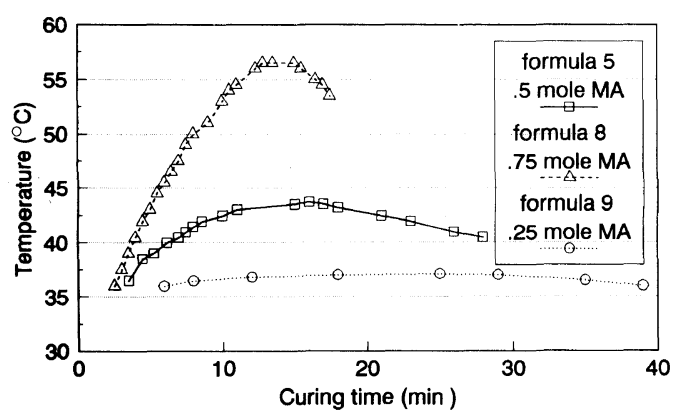

Figure 2. Curing exotherms for UP formulae 5, 8, and 9.

structural principles affecting the amount of heat liberated during curing reactions.

\section{Effect of Resin Chemistry of the Mechanical Properties}

As a sample is loaded, a force (stress) versus extension (strain) curve is recorded. The derived values of Young's modulus in GPa and $\sigma_{\mathbf{u}}$ in $\mathrm{MPa}$ are tabulated in Table II. The data shows that formulae $1,4,5$, and 8 are rigid resins meanwhile the other formulae are flexible. Table II reveals that the formulae having the same phthalic-maleic-syrene ratio, the Young's modulus $(E)$ decreases from 0.828 $\mathrm{GPa}$ to $0.8 \mathrm{GPa}$ with replacing half of the quantity of $\mathrm{EG}$ by its equivalent moles of PG. Increasing the average molecular weight of the utilized glycol mixture for preparing the UP, by replacing EG in formula No. 4 wih DG in formula No. 5 , leads to a further reduction in $\mathrm{E}$ which was recorded as $0.728 \mathrm{GPa}$. When the amount of PHA is reduced from $0.5 \mathrm{~mol}$ to $0.25 \mathrm{~mol}$ accompanied with increasing MA from 0.5 to $0.75 \mathrm{~mol}$, as in case of formula No. 8, an intense increase in $E(1.372 \mathrm{GPa})$ is observed. The obtained results runs in harmoney with the literature. ${ }^{16}$ When only $0.25 \mathrm{~mol} \mathrm{MA}$ is used in conjunction with $0.75 \mathrm{~mol}$ PHA, the value of Young's modulus is completely vanish and the resin switches from rigid to flexible. From the above mentioned results, one can conclude that decreasing the polymerizable double bonds, i.e., the ratio of $\mathrm{MA}$, and increasing the molecular weight of the glycol components incorporated in the copolymer leads to an abridgment in Young's modulus of the final product. The above mentioned discussion persuades the speculation that the introduction of a tenuous network of primary chemical-bond crosslinks to the aliphatic chains does not completely restrict the local freedom of motion of these chains. Accordingly, as the length of the polymer segment increases, many conformations can be held and the flexibility increases.

The range of the measured Young's modulus in the present study runs in harmony with the recent values published in the literature. In this respect, it is of interest to mention that Rebeiz et $a{ }^{17}{ }^{17}$ developed an experimental design to study the effect of different percentages of recycled poly(ethylene terephthalate) (PET) on the mechanical properties of the resins and the polymer concrete including these resins. The effect of the amount of the PET residues in the resin on its mechanical properties was studied by the same authors. ${ }^{1}$ They showed that a slight increase in PET from $28 \%$ to $30 \%$ leads to a remarkable reduction in Young's modulus from $3.38 \mathrm{GPa}$ to $0.3 \mathrm{GPa}$. In other studies Paul and his coworkers ${ }^{3,5}$ recorded values for Young's modulus ranging between $0.41 \mathrm{GPa}$ and $4.9 \mathrm{GPa}$ for clear cast resins based on recycled PET. The very recent values of 1.24 GPa and $0.3 \mathrm{GPa}$ were published by Rebeiz et $a l .{ }^{4}$ for another two polyester resins having different PET percentages. All the above mentioned values illustrate the magnanimous sensitivity of Young's modulus to the structure of the cured resin.

The dependence of the compressive strength $\left(\sigma_{u}\right)$ on the composition of the resin may be explained with the aid of Table II. This table shows that the value of $\sigma_{\mathrm{u}}$ in MPa depends to a large extent on the structure of the resin. The highest value of $\sigma_{\mathrm{u}}$ for the resins was found for formula No. 8 at which the ratio of PHA/MA being $1: 3$. This can be explained by increasing the cross-linking density. With respect to formulae No. 2, 3, 6, 7, and 9, the stress- 
strain curves showed no yield points due to its flxibility. Consequently, no Young's moduli are obtained. The lowest value of $\sigma_{\mathrm{u}}$ is obtained for copolymr No. 9 for which MA/PHA ratio is $1: 3$. This may confirm the previously mentioned speculation of the effect of the cross-linking density on the value of $\sigma_{u}$. At the same time, the effect of molecular weight of the glycol on the value of $\sigma_{\mathrm{u}}$ is detected, where its highest value is achieved where $\mathrm{EG}+\mathrm{DG}$ are used in constructing the resin (formula No. 2). The quoted values of $\sigma_{\mathrm{u}}$ in Table II seems to be in good accord with the range of values reported by Piggott and Harris. ${ }^{18}$

\section{CONCLUSION}

The exotherm temperatures and curing time of unsaturated polyester resins can be manipulated per processing requirements by varying the relative amounts of two glycols, having different molecular weights, incorporated in manufacturing the unsaturated polyester resins. It has been established that the maximum curing temperature, $T_{\max }$, is related to the average molecular weight of the glycols incorporated in the unsaturated polyester. In this context the $T_{\max }$ is decreased with increasing the molecular weight. In contrast to $T_{\max }$ the time to peak temperature $\left(t_{\max }\right)$ is increasing with increasing the molecular weight of the glycol. Unsaturated polyester resin, formula 4 would be best suited for processes like large object molding, where a low temperature is desirable. This formula would definitely benefit the large moulding industries by offering versatility in processing due to the low exotherm temperature and reasonably long curing time over other formulae adding to that the resonable rigidity experienced by this formula.

\section{REFERENCES}

1. K. S. Rebeiz, D. W. Fowler, and D. R. Paul, Plast. Eng., (February), 33 (1991).

2. U. R. Vaidya and V. M. Nadkarni, Ind. Eng. Chem. Res., 26, 194 (1987).

3. K. S. Rebeiz, D. W. Fowler, and D. R. Paul, Polym.-Plast. Technol. Eng., 30, 809 (1991).

4. K. S. Rebeiz, D. W. Fowler, and D. R. Paul, J. Appl. Polym. Sci., 44, 1649 (1992).

5. K. S. Rebeiz, D. W. Fowler, and D. R. Paul, "Proceedings of the Third International Symposium for Mechanics of Polymer Composites," the Institute of Theoretical and Applied Mechanics of the Czechoslovak Society for Mechanics, Working Group on Composite Materials and Systems, Prague, 16th-18th April, 1991, p 367.

6. E. S. Nasr and A. A. Abdel-Azim, Polym. Adv. Technol., 3, 407 (1992).

7. W. R. Sorenson and T. W. Campbell, "Preparative Method of Polymer Chemistry," Interscience, New York, 1968, p 155.

8. J. Urbanski, W. Czerwinski, K. Janika, F. Majewska, and H. Zowall, "Handbook of Analysis of Synthetic Polymers and Plastics," Ellis Horwood, Chester, England, 1977.

9. F. W. Billmeyer, Jr., "Textbook of Polymer Science," 2nd ed, Wiley-Interscience, New York, 1971.

10. H. A. Pohl, Anal. Chem., 26, 1614 (1954).

11. A. Conix, Makromol. Chem., 26, 226 (1958).

12. V. Larez, J. Cristobal, and A. Cilberto, Polym. Bull., 26, 313 (1991).

13. V. Larez, J. Cristobal, P. Mendoza, and A. Gilberto, Polym. Bull., 22, 513 (1989).

14. V. Larez, J. Cristobal, P. Mendoz, and A. Gilberto, Polym. Bull., 23, 577 (1990).

15. K. Horie, I. Mita, and H. Kambe, J. Polym. Sci., $A-1,8,2839$ (1970).

16. C. A. Harper, Ed., "Handbook of Plastics and Elastomers," McGraw Hill Inc., New York, 1975.

17. K. S. Rebeiz, V. S. Lyer, D. W. Fowler, and D. R. Paul, "Proceeding of the 48th Annula Technical Conference of the Society of Plastics Engineers (ANTEC 90)," Dallas, Texas, 1990.

18. M. R. Piggott and B. Harris, J. Mater. Sci., 15, 2523 (1980). 